\title{
Perfil Geoecológico do Parque Nacional da Serra do Gandarela, Minas Gerais, Brasil
}

\author{
Geoecological profile of the Serra do Gandarela National Park, Minas Gerais, Brazil
}

\author{
Darcy José dos Santos ${ }^{1}$ \\ Úrsula de Azevedo Ruchkys ${ }^{2}$ \\ Luiz Eduardo Panisset Travassos 3 (i)
}

\begin{abstract}
Palavras-chave:
Perfil geoecológico.

PARNA Serra do Gandarela.

Minas Gerais.
\end{abstract}

\begin{abstract}
Resumo
Este trabalho apresenta uma leitura geossistêmica do Parque Nacional da Serra do Gandarela. Esta unidade de conservação está inserida no contexto do Quadrilátero Ferrífero, em Minas Gerais, onde afloram unidades litoestratigráficas dos supergrupos Rio das Velhas e Minas, de idade pré-cambriana. Para realizar esta leitura foi elaborado um perfil geoecológico. Este método consiste na representação cartográfica de transectos sobre a área de interesse, o que favorece a realização de leituras horizontais ao longo de cada elemento representado e, também, leituras verticais, onde podem ser interpretadas correlações entre os diversos elementos presentes. Os compartimentos dos domínios morfoestruturais elaborados para o Projeto APA Sul da Região Metropolitana de Belo Horizonte foram utilizados como unidades de análise para interpretação deste perfil geoecológico. O perfil geoecológico construído permitiu uma compreensão mais holística da área de estudo, o que poderá contribuir para a gestão desta unidade de conservação.
\end{abstract}

Keywords:

Geoecological profile.

Serra do Gandarela National Park

Minas Gerais

\begin{abstract}
This paper presents a geosystemic study of the Serra do Gandarela National Park. This conservation unit is inserted in the context of the Quadrilátero Ferrífero, in Minas Gerais, where outcrops of Precambrian lithostratigraphic units of the Rio das Velhas and Minas Supergroups can be found. Thus, a geoecological profile was elaborated using a methodology of cartographic representation of a transect on the area of interest. This favours the elaboration of horizontal readings along with each represented element, as well as vertical readings, where correlations can be interpreted between the various elements present. The compartments of the morphostructural domains elaborated for the Belo Horizonte Southern Metropolitan Region Environmental Protection Area Project (Projeto APA Sul da Região Metropolitana de Belo Horizonte) were used as units of analysis for interpretation of the geoecological profile. The constructed geoecological profile enabled a more holistic understanding of the study area, which may contribute to the management of this conservation unit.
\end{abstract}

${ }^{1}$ ICMBio/CECAV, Nova Lima, MG, Brasil. darcymgsantos@ hotmail.com

${ }^{2}$ Universidade Federal de Minas Gerais, Instituto de Geociências, Belo Horizonte, MG, Brasil. tularuchkys@yahoo.com.br

${ }^{3}$ Pontifícia Universidade Católica de Minas Gerais, Belo Horizonte, MG, Brasil. luizepanisset@ gmail.com 


\section{INTRODUÇÃO}

A abordagem geossistêmica busca articular variáveis "antrópicas" e "naturais", para construir uma análise holística do ambiente (MONTEIRO, 2001). Embasado nos trabalhos de Bertalanffy (1950), que compreendia os Geossistemas como uma categoria específica de sistemas dinâmicos estruturados de forma hierárquica, Sotchava (1977) propõe utilizá-los para a compreensão dos fenômenos geográficos. Destaca a hierarquia de construção com a característica principal dos geossistemas, onde todas as subdivisões do meio natural, desde as unidades mínimas da superfície terrestre até o geossistema planetário caracterizam-se como unidades dinâmicas, com organizações geográficas específicas. Assim, para este autor, o arcabouço sistêmico não se limita à morfologia ou subdivisões da paisagem, mas busca, sobretudo compreender sua dinâmica e estrutura (SOTCHAVA, 1977).

Para Bertrand (1972), a paisagem é resultante da interação dialética entre elementos físicos, biológicos e antrópicos, em constante evolução, constituindo-se num conjunto único, espacialmente localizado. Este autor desenvolve um sistema para classificação hierárquica composta por seis níveis: Zona, Domínio, Região Natural, Geossistema, Geofácies e Geótopo. Nesta taxonomia, o Geossistema compreende uma unidade que integra dinamicamente fatores geomorfológicos, climáticos e hidrológicos, apresenta o mesmo tipo de evolução, sólida unidade biológica e ecológica e, muitas vezes, fisionomia homogênea. Na mesma perspectiva, Ramos et al. (2019) defendem que a superfície terrestre pode ser compreendida como unidade espacial que possui uma dinâmica de interações entre processos naturais e antrópicos, compondo assim uma relação sistêmica.

Partindo dos conceitos apresentados acima, Marés Mikosik et al. (2009) consideram que a construção de perfis geoecológicos são uma forma de abordagem sistêmica da paisagem. $\mathrm{Na}$ mesma linha, Levighin e Viadana (2003) apontam que este método explicita os aspectos ambientais da área em análise, uma vez que permite representar secções do espaço e estabelecer correlações entre seus elementos.

Estas premissas têm embasado diferentes estudos utilizando perfis geoecológicos para realização de análises integradas da paisagem, especialmente voltadas para a compreensão e gestão em unidades de conservação (JANSEN, 2014; MARENT; PORTILHO, 2017; LOPEZ; LEÃO, 2018; SANTOS et al., 2018; RAMOS et al., 2019).

\section{ÁREA DE ESTUDO}

O Parque Nacional da Serra do Gandarela (PNSG), unidade de conservação da categoria de proteção integral, foi criado em outubro de 2014, com área de 31.270 hectares. Ocupa parte dos municípios de Nova Lima, Raposos, Caeté, Santa Bárbara, Mariana, Ouro Preto, Itabirito e Rio Acima. Localizado a cerca de $50 \mathrm{~km}$ de Belo Horizonte, no Estado de Minas Gerais, tem como objetivo:

Garantir a preservação de amostras do patrimônio biológico, geológico, espeleológico e hidrológico associado às formações de canga do Quadrilátero Ferrífero, incluindo os campos rupestres e os remanescentes de floresta semidecidual, as áreas de recarga de aquíferos e o conjunto cênico constituído por serras, platôs, vegetação natural, rios e cachoeiras (BRASIL, 2014).

Esta unidade de conservação está inserida no contexto do Quadrilátero Ferrífero (QF), onde afloram as unidades litoestratigráficas dos supergrupos Rio das Velhas e Minas, de idade pré-cambriana. Ocorrem ainda, em menor escala, depósito lacustrino, coberturas detritolateríticas, depósitos coluviais e elúvio-coluviais, de idade cenozoica, além de depósitos aluviais, constituídos por rochas fanerozoicas (Figura 1).

Diferentes tipos litológicos, com múltiplos graus de resistência ao intemperismo químico e à erosão, combinados a complexos condicionamentos estruturais, marcados por dobramentos e falhas de empurrão, além de soerguimento tectônico cenozoico e fatores bioclimáticos condicionaram o modelado dos compartimentos morfoestruturais encontrados no QF, em sua origem e evolução (MEDINA; DANTAS; SAADI, 2005). Dentre as unidades morfoestruturais propostas por estes autores para o $\mathrm{QF}$, seis foram identificadas na área de estudo: Vale Anticlinal do Rio das Velhas, Patamares escalonados da Serra do Jaguara, Depressão Suspensa do Sinclinal Gandarela, 
Vale Anticlinal do Rio Conceição, Crista Sinclinal da Serra do Ouro Fino e Maciço do Caraça.

A diversidade de litotipos aflorantes no PNSG favorece a ocorrência de grande quantidade de cavidades naturais subterrâneas. O Cadastro Nacional de Informações Espeleológicas - CANIE apontava em dezembro de 2019, a ocorrência de 275 cavernas na área do parque, desenvolvidas em rochas carbonáticas, ferríferas e siliciclásticas. O parque está situado em área onde predomina potencial entre médio, alto e muito alto para ocorrência de cavernas (JANSEN; CAVALCANTI; LAMBLÉM, 2012), por isso novas cavernas poderão vir a ser localizadas na região, à medida que forem realizados trabalhos de prospecção espeleológica.

A cobertura pedológica, fortemente determinada pelo material de origem, é composta principalmente por Cambissolos Háplicos e Neossolos, que ocupam cerca de $75 \%$ da área. Shinzato e Filho (2005) apontam que estes tipos de solos são pouco desenvolvidos, rasos ou pouco profundos, apresentando grande concentração de minerais e baixa resistência ao intemperismo, estando associados a relevos movimentados. Estas características, combinadas com períodos de grande precipitação, com maiores velocidades de escoamento superficial, favorecem processos morfogenéticos. Aproximadamente 20\% da área apresenta cobertura de solo pouco espessa ou inexistente, composta por afloramentos rochosos, exposições de canga ou áreas degradadas. O restante da área apresenta Argissolos, Latossolos e Gleissolos.

\section{Figura 1- Parque Nacional da Serra do Gandarela - Geologia}

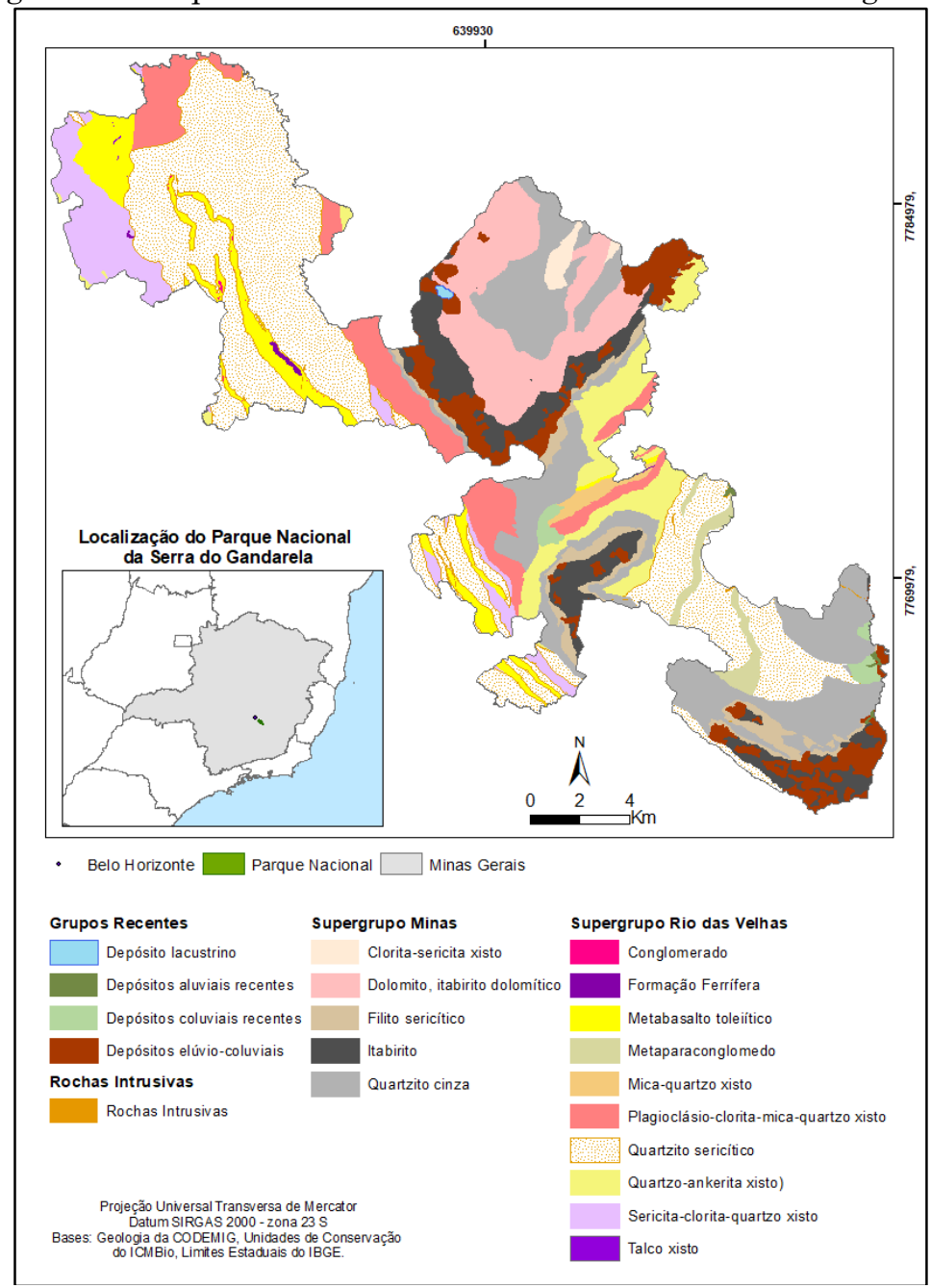

Fonte: Elaborado pelos autores. 
O PNSG situa-se em área de transição entre os biomas Cerrado e Mata Atlântica. O mapa de Cobertura e Uso da Terra elaborado por Oliveira, Jacques e Shinzato (2005) para o projeto APA Sul RMBH indica a prevalência das fitofisionomias Campo Cerrado/Campo Graminoso e Mata. Em menor escala, indicam a ocorrência de outras coberturas, incluindo de Campo Rupestre, além da classe de uso "Solo Exposto". Os autores apontam que a classe Campo Rupestre, nesta área, associa-se às coberturas de canga e aos afloramentos quartzíticos. Lamounier et al. (2010); Filho, Curi e Shinzato (2010) avançam na análise da relação entre litologia e cobertura. Para estes autores, a variação litológica é determinante no estabelecimento e desenvolvimento das fitofisionomias encontradas na região. Estes descrevem que as rochas dos grupos Itabira, Caraça e Maquiné, com maior resistência ao intemperismo, condicionam as maiores altitudes associando-se à ocorrência dos campos rupestres quartzíticos e ferruginosos. Campos limpos e sujos, fitofisionomias do Cerrado, estão relacionados à ocorrência das rochas do Grupo Nova Lima. As áreas onde Floresta Estacional Semi-decidual pôde se estabelecer apresentam camadas mais profundas de solos, desenvolvidos a partir das rochas da Formação Gandarela e filitos do Grupo Piracicaba, mais suscetíveis aos processos pedogenéticos.

Esta região é historicamente marcada pela exploração mineral, especialmente de minério de ferro. Destaca-se que, conforme apresentado por Piló, Coelho e Reino (2015), o QF juntamente com a Serra dos Carajás, no Pará, respondem por mais de $90 \%$ da produção nacional deste minério. Assim, a rigidez locacional das reservas de ferro têm sido utilizadas como argumento para a instalação e ampliação de empreendimentos minerários impondo grande pressão sobre áreas que, como apresentado por Carmo (2010), são insubstituíveis por apresentarem altos índices de endemismos, ocorrência de espécies raras e geodiversidade singular com diversas categorias de patrimônio associadas.

Souza e Carmo (2015) classificam estas áreas como geossistemas ferruginosos, definidos como unidades espaciais cuja litologia é composta por rochas ferruginosas originadas principalmente no Arqueano $(2,7 \quad-2,6 \quad \mathrm{Ga})$ e no Paleoproterozoico (2,5 Ga a $540 \mathrm{Ma})$. Estes geossistemas incluem os componentes físicos e as inter-relações entre eles, guardando elementos naturais importantes como recursos hídricos, endemismos de flora e fauna e patrimônio espeleológico. Salgado (2015) argumenta que estes geossistemas estão classificados entre os mais expressivos da superfície terrestre, em razão da riqueza de sua geodiversidade e biodiversidade. Entretanto, este autor salienta que, onde a exploração minerária ocorreu de forma mais intensa nestes geossistemas, sua geodiversidade, ainda pouco estudada e conhecida, sofreu degradação e, em muitos casos, destruição de seus elementos.

Além de proteger parte bem conservada dos geossistemas ferruginosos, esta unidade de conservação reflete a complexidade geológica e ambiental do QF, auxiliando em sua conservação. A Empresa Vale S.A. e a Amplo Engenharia e Gestão de Projetos Ltda., em 2019, por meio de análises da natureza do substrato, identificaram nos limites deste parque nacional, além do Geossistema Ferruginoso, um Geossistema Quartzítico e outro Metapelítico.

\section{METODOLOGIA}

Para melhor compreensão tanto da distribuição espacial, quanto das relações entre os elementos abióticos e a cobertura vegetal na área de estudo, foi elaborado um perfil geoecológico. Este método consiste na representação cartográfica de transectos sobre a área de interesse, o que favorece a realização de leituras horizontais ao longo de cada elemento representado e, também, leituras verticais, onde podem ser interpretadas correlações entre os diversos elementos em determinado local (MONTEIRO, 2001; LEVIGHIN; VIADANA, 2003).

Os compartimentos dos domínios morfoestruturais elaborados para o Projeto APA Sul da Região Metropolitana de Belo Horizonte (MEDINA; DANTAS; SAADI, 2005) foram utilizados como unidades de análise para interpretação deste perfil geoecológico. Para tanto, criou-se um transecto com cerca de trinta quilômetros no sentido noroeste-sudeste, de modo a interceptar todos os compartimentos morfoestruturais existentes na área do parque (Figura 2). Este transecto parte do ponto A, localizado na porção noroeste da área, às coordenadas UTM 624223 e 7786758, até o ponto $\mathrm{B}$, na porção sudeste, localizado às coordenadas 647906 e 7771076 .

As análises propostas pelo artigo foram realizadas em um Sistema de Informações Geográficas. Após a definição do transecto, elaborou-se um perfil topográfico, utilizando 
imagens SRTM (s20w044 e s21w044), com resolução de 30 metros, com o auxílio do software TrackMaker. Em seguida, este perfil topográfico foi sobreposto às informações (shapes) referentes à geologia, geomorfologia, pedologia e cobertura e uso da terra (Projeto APA Sul da RMBH - CPRM, 2005), limites municipais (IBGE), e mapa do Potencial de Ocorrência de Cavernas (JANSEN; CAVALCANTI; LAMBLÉM, 2012).

Esta etapa foi realizada por meio do software ArcGIS. As análises em escritório foram acompanhadas por visitas a campo para melhor interpretação do perfil.

\section{RESULTADOS}

O perfil geoecológico (Figura 3) permitiu a realização de leituras verticais e horizontais, com vistas a uma compreensão holística da área de estudo.

\section{Figura 2- Parque Nacional da Serra do Gandarela - Unidades Morfoestruturais}

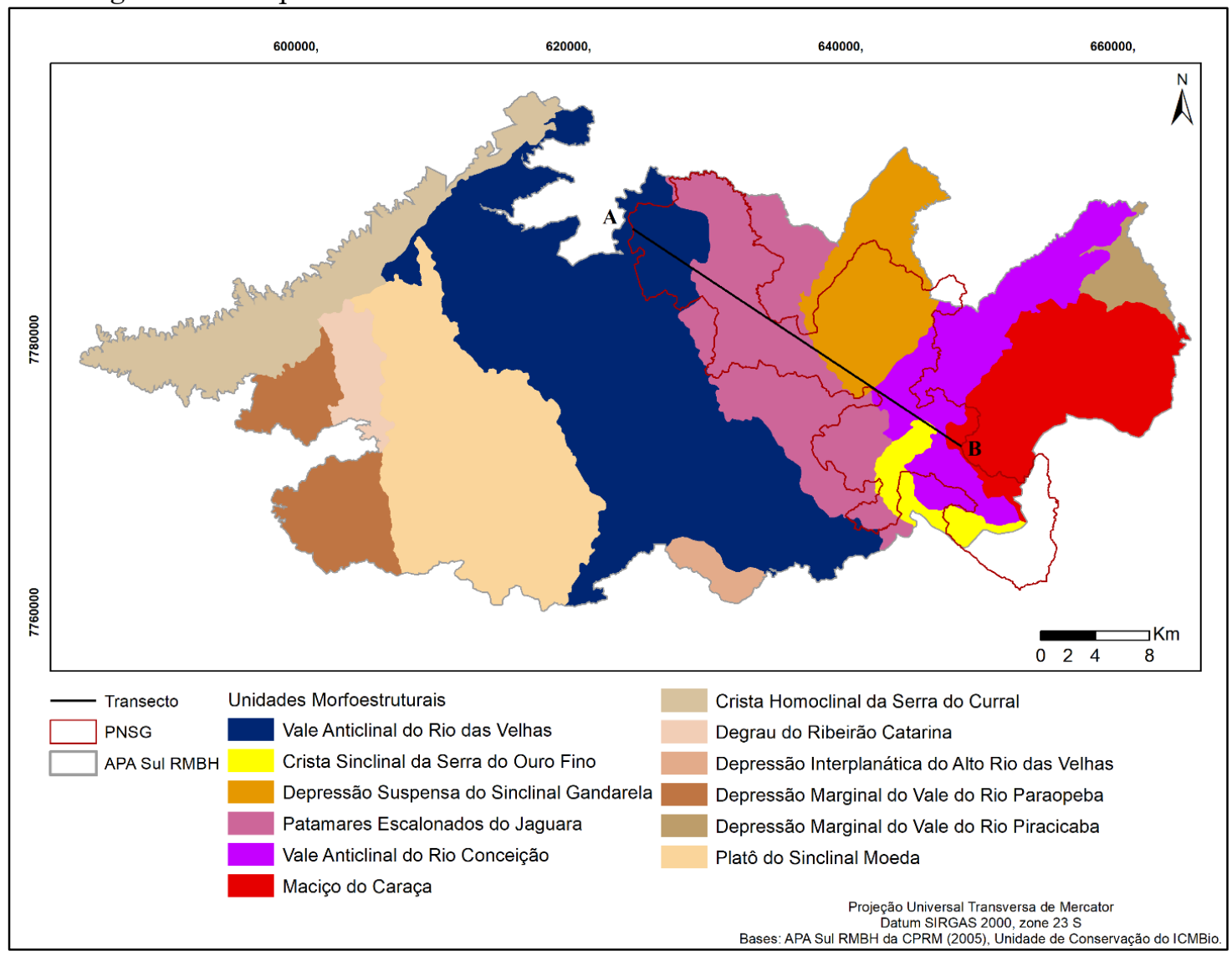

Fonte: Elaborado pelos autores.

O compartimento Vale Anticlinal do Rio das Velhas situado no noroeste da área de estudo, abrange parte dos municípios de Nova Lima e Raposos. Neste compartimento predomina vegetação de cerrado (campo cerrado e campo graminoso), ocorrendo matas ciliares ao longo dos corpos d'água. Os solos são compostos por Cambissolos Háplicos (distrófico típico e distrófico léptico ou lítico) e Neossolos (distrófico típico) de textura muito cascalhenta e Argissolos (vermelho-amarelo distrófico câmbico ou típico). O relevo é dominado por morros de topos ou cristas aguçados, sustentados por rochas do
Supergrupo Rio das Velhas, datadas do Mesoarqueano-Neoarqueano, localmente representadas pelos litotipos Metagrauvaca, metatufo, siltito, xisto carbonoso, metadensito e Metabasalto, metatufo, metavulcânica ácida, metachert, xisto carbonoso, ambos do Grupo Nova Lima e Xistos com intercalações de quartzitos do Grupo Maquiné. Esta região apresenta potencial médio para a ocorrência de cavidades naturais subterrâneas.

O compartimento Patamares escalonados do Jaguara, incidente no trecho do parque situado nos municípios de Rio Acima e Caeté, apresenta 
altimetria variando, aproximadamente, entre 1.000 , em sua porção mais a noroeste e 1.500 metros, mais a sudeste. $\mathrm{Na}$ vegetação, predominam os tipos vegetacionais campo cerrado / campo graminoso, típicos do cerrado. Coberturas de mata ocorrem associadas a corpos d'água. A existência de estradas não pavimentadas expõe a cobertura pedológica, constituída essencialmente por Cambissolos e Neossolos. Em diversos trechos, a inexistência ou baixa profundidade dos perfis pedológicos permite o afloramento do substrato rochoso. $\mathrm{O}$ relevo é dominado por serras/patamares, platôs quartzíticos, esporões e escarpas. Neste trecho predominam rochas siliciclásticas do Supergrupo Rio das Velhas, representadas pelos litotipos Quartzitos e conglomerados, Quartzitos com intercalações de metaconglomerados e Xistos com intercalações de quartzitos, todos do Grupo Maquiné, Quartzo-mica xisto, xisto carbonoso, formação ferrífera e Mica-quartzo xisto, xisto grafitoso, ambos do Grupo Nova Lima. Onde o transecto se aproxima do próximo compartimento (Depressão Suspensa do Sinclinal Gandarela) começam a aflorar rochas do Supergrupo Minas, associadas a relevo de escarpas. Neste trecho são identificados os litotipos Quartzito conglomerado e filito, Filito com intercalações de metachert e Itabirito, itabirito dolomítico e corpos de hematita, de idade Paleoproterozóica, além de coberturas de canga, de idade cenozoica, na transição entre os compartimentos. Este compartimento apresenta potencial para ocorrência de cavernas variando de médio, em sua porção oeste, a alto, mais para leste, à medida que atinge maiores altitudes e alcança as coberturas de canga.

O compartimento Depressão Suspensa do Sinclinal Gandarela apresenta as maiores altitudes do perfil, variando entre 1.300 e 1.600 metros, ocupando áreas dos municípios de Rio Acima e, principalmente, Santa Bárbara. Predomina vegetação de campo cerrado / campo graminoso, ocorrendo trechos de matas associados a drenagens. Nas partes mais altas ocorrem campos rupestres. A cobertura pedológica, quando presente, é constituída por Neossolos. Nos outros trechos, onde está ausente, depósitos eluvio-coluviais, formados por fragmentos de hematita e itabirito cimentados por limonita (canga), criam superfícies aplainadas sustentando as maiores altitudes deste compartimento, por volta dos 1.600 metros. Atividades minerárias degradaram parte desta cobertura. O relevo é constituído principalmente por escarpas, intercaladas por platôs lateríticos. Estas formas de relevo estão sustentadas por rochas constituídas pelos litotipos Itabirito, itabirito dolomítico e corpos de hematita, do Supergrupo Minas e por Fragmentos de itabirito e hematita compacta, cimentados por limonita (Canga). Este compartimento apresenta os maiores potenciais para ocorrência de cavernas, devido à presença dos itabiritos nas partes elevadas do relevo e dos dolomitos da Formação Gandarela, no interior da depressão suspensa.

O compartimento Vale anticlinal do Rio Conceição teve dois trechos interceptados pelo perfil, ambos no município de Santa Bárbara. Apresenta altitudes variando entre 1.500 metros, próximo ao compartimento do Sinclinal Suspenso do Gandarela, e 950 metros, no leito do rio Conceição. A vegetação é composta por fitofisionomias de menor porte, campo cerrado / campo graminoso, nas partes mais elevadas e matas, nos trechos mais baixos. A cobertura pedológica é constituída por Cambissolos e Neossolos. Entretanto, em grandes extensões, ocorrem afloramentos rochosos, seja pela exposição da canga ou de outras rochas. O relevo apresenta platô laterítico e colinas, no trecho mais elevado do compartimento no perfil. Estes são sustentados pela canga e pelo litotipo Itabirito, itabirito dolomítico e corpos de hematita, do Supergrupo Minas. Nos trechos de maior variação altimétrica, entre 1.450 e 950 metros, predominam os esporões. Estes, por sua vez, apresentam grande diversidade litológica. Nos trechos mais baixos, coincidindo com os leitos do rio Conceição e do córrego do Sarame, ocorre o litotipo Mica-quartzo xisto, xisto grafitoso, do Supergrupo Rio das Velhas. Nas outras áreas deste compartimento no perfil, ocorrem rochas do Supergrupo Minas, representadas pelos litotipos Quartzito, conglomerado e filito e Filito com intercalações de metachert e, do Supergrupo Rio das Velhas, os litotipos Quartzo-clorita sericita xisto, com intercalações de formações ferríferas e Metabasalto, metatufo, metavulcânica ácida, metachert, xisto carbonoso. Em sua porção mais a leste, este compartimento apresenta potencial alto para a ocorrência de cavernas, devido à presença dos itabiritos. Em sua porção mais a leste, onde predominam quartzitos, apresenta potencial médio para este tipo de ocorrência. 
Figura 3- O Perfil Geoecológico do PARNA Serra do Gandarela.

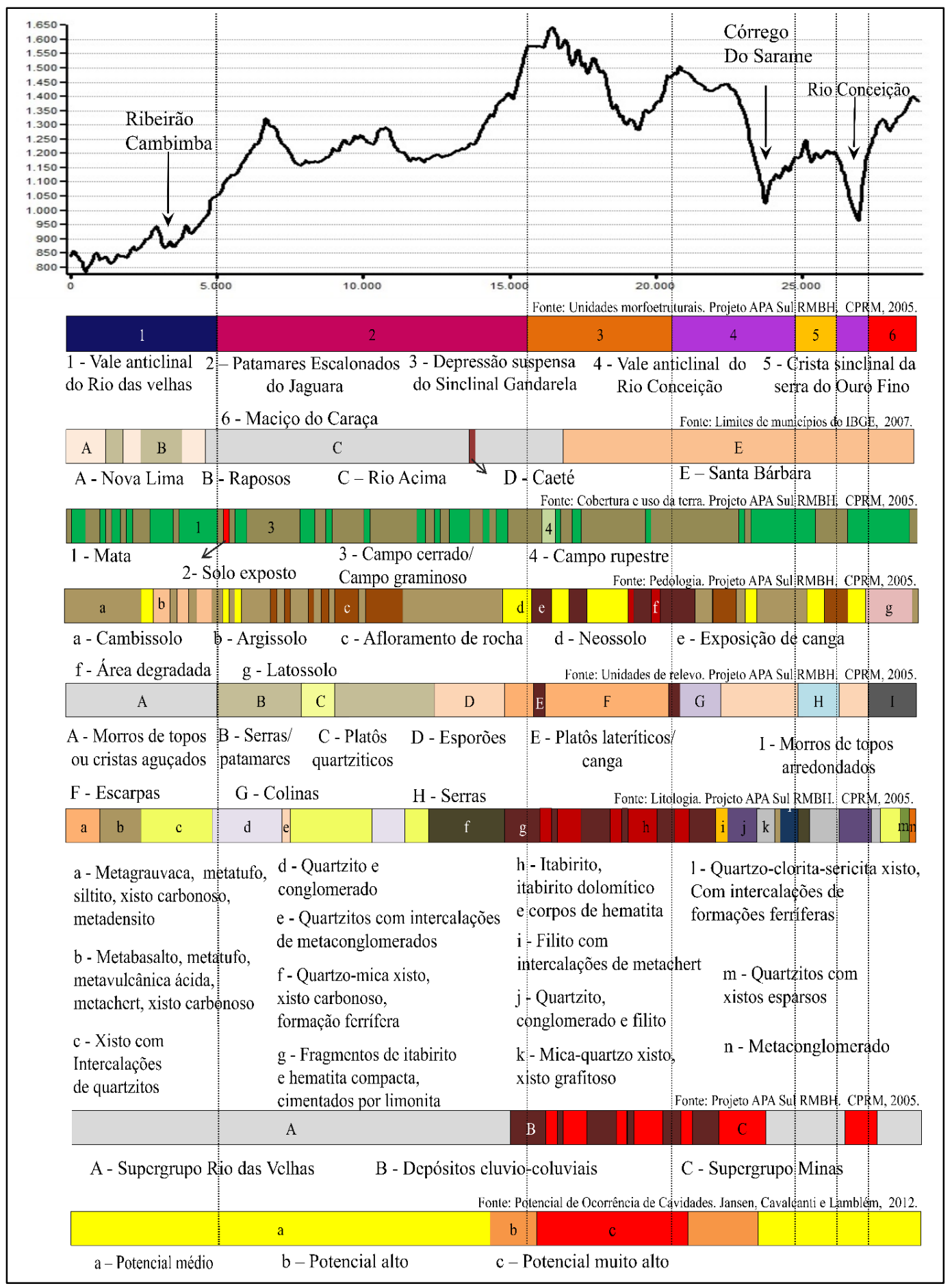

Fonte: Elaborado pelos autores.

O trecho do compartimento Crista Sinclinal da Serra do Ouro Fino representado no perfil está inserido no município de Santa Bárbara e apresenta altitudes em torno dos 1.250 metros. Predomina vegetação de porte herbáceoarbustivo, constituída de campo cerrado / campo graminoso, sobre camada pedológica composta por Cambissolos e Neossolos, além de trecho onde a rocha está aflorante. O relevo é caracterizado pela presença de serras sobre rochas do Supergrupo Rio das Velhas, localmente representadas pelos litotipos Quartzo-mica xisto, xisto grafitoso e Quartzomica xisto, xisto carbonoso, formação ferrífera. Este compartimento apresenta potencial médio para ocorrência de cavidades naturais. 
O compartimento Maciço do Caraça está representado em pequeno trecho, no extremo sudeste do perfil, no município de Santa Bárbara, apresentando altitudes entre 1.200 e 1.400 metros. A cobertura vegetal é formada, em sua quase totalidade, por mata, desenvolvida sobre os solos mais profundos do perfil, constituídos por latossolos. Em menor proporção ocorrem fitofisionomias campestres, sustentadas por Cambissolos. O relevo é marcado por morros de topos arredondados, esculpido sobre rochas do Supergrupo Minas, onde são identificados os litotipos Mica-quartzo xisto, xisto grafitoso, Xistos com intercalações de quartzitos, Quartzitos com seixos esparsos e Metaconglomerados. Neste compartimento, o predomínio de rochas siliciclásticas propiciam a prevalência de potencial médio para ocorrência de cavernas.

$\mathrm{O}$ perfil evidenciou alguns desafios para a gestão desta unidade de conservação. De modo geral, pode-se afirmar que o predomínio de Neossolos, Cambissolos pouco desenvolvidos e afloramentos rochosos associados a relevo movimentado e cobertura vegetal composta por fitofisionomias herbáceas e arbustivas condicionam graus elevados de vulnerabilidade ambiental no Parque Nacional da Serra do Gandarela (Santos, 2017). Este fator pode ser verificado em trechos nos compartimentos Vale Anticlinal do Rio das Velhas e Patamares Escalonados do Jaguara. Locais onde a cobertura vegetal foi suprimida, principalmente pela prática de motocross ou para construção de acessos a cachoeiras, sofreram intenso processo erosivo, chegando, inclusive a expor a rocha subjacente. A grande e, às vezes, abrupta variação altimétrica favorece a ocorrência de mirantes e cachoeiras, operando como atrativo turístico para a prática de esportes de aventura e atividades ao ar livre. Por outro lado, esta mesma movimentação do relevo, associado a solos pouco desenvolvidos favorece a prevalência de processos morfogenéticos, reforçando a importância de planejamento criteriosos tanto para a instalação de infraestrutura para utilização dos atrativos do parque, quanto para a urgência em recuperar áreas que foram degradadas pelo uso anterior à criação deste parque.

Outro desafio evidenciado, também relacionado à vulnerabilidade ambiental, diz respeito aos campos rupestres ferruginosos, intrinsecamente associados aos geossistemas ferruginosos. especialmente na transição entre os compartimentos Patamares Escalonados do Jaguara e Depressão Suspensa do Gandarela.
Esta vegetação é sustentada por delgada camada de matéria orgânica disposta diretamente sobre a rocha, constituída na maior parte por canga. Em pontos onde este solo incipiente foi removido, para realização de pesquisa mineral ou exploração de bauxita, não ocorreu o repovoamento espontâneo da vegetação, mesmo após o transcurso de algumas décadas.

\section{CONCLUSÕES}

O perfil geoecológico representa as características da paisagem na forma de transecto. Para elaboração do perfil geoecológico do Parque Nacional da Serra do Gandarela foram utilizados os elementos abióticos (solos, unidades de relevo, unidades morfoestruturais, litologia e potencial de ocorrência de cavernas) e bióticos (uso do solo e cobertura vegetal).

A representação estrutural da paisagem em forma de transecto demonstrou um comportamento variável do potencial de ocorrência de cavernas, sendo que o compartimento com maior potencial é Depressão Suspenda do Sinclinal Gandarela.

O uso dessa técnica permitiu ainda evidenciar desafios para a gestão da Unidade de Conservação em especial relativos: aos processos erosivos causados pela prática de motocross ou para acesso a cachoeiras que indicam alta vulnerabilidade ambiental; áreas com prevalencia de processos morfogenéticos associados a solos pouco desenvolvidos; supressão da vegetação de campo rupestre ferruginoso decorrente de usos passados para pesquisa ou exploração mineral sem recomposição espontâneo da vegetação.

Os resultados indicam que o perfil geoecológico pode servir como subsídio para a minimização de impactos ambientais negativos bem como para o planejamento e gestão da unidade de conservação, refletidos em seu plano de manejo que ainda está em elaboração.

\section{REFERÊNCIAS}

BERTALANFFY, LV, An outline of general system theory. The British Journal for the Philosophy of Science, v. 1, n. 2, p. 134-165., 1950 Disponível em <http://www.isna ture.org/Events/2009/Summer/r/Bertalanffy19 50-GST_Outline_SELECT.pdf> 
BERTRAND, Georges. Paisagem e geografia física global. esboço metodológico. Caderno de Ciências da Terra, São Paulo, v. 13, p. 141152,1972

BRASIL. PRESIDÊNCIA DA REPÚBLICA. Decreto s/no, de 13 de outubro de 2014. Cria o Parque Nacional da Serra do Gandarela, localizado nos Municípios de Nova Lima, Raposos, Caeté, Santa Bárbara, Mariana, Ouro Preto, Itabirito e Rio Acima, Estado de Minas Gerais. 2014. Disponível em <https://www.planalto.gov.br/CCIVIL_03/_Ato 2011-2014/2014/Dsn/Dsn14013.htm>. Acesso em: 10 mar. 2016.

CARMO, F. F. Importância ambiental e estado de conservação dos ecossistemas de cangas no Quadrilátero Ferrífero e proposta de áreasalvo para a investigação e proteção da biodiversidade em Minas Gerais. 2010. 90 f. Dissertação (Mestrado em Ecologia, Conservação e Manejo da Vida Silvestre) Instituto de Ciências Biológicas, Universidade Federal de Minas Gerais, 2010.

FILHO, A. D. C.; CURI, N.; SHINZATO, E. Relações solo-paisagem no Quadrilátero Ferrífero em Minas Gerais. Pesquisa Agropecuária Brasileira, v. 45, n. 1, p. 903916, 2010. https://doi.org/10.1590/S0100204X2010000800017

JANSEN, D. C.; CAVALCANTI, L. F.; LAMBLÉM, H. S. Mapa de potencialidade de ocorrência de cavernas no Brasil, na escala 1:2.500.000. Revista Brasileira de Espeleologia, v. 2, p. 42-57, 2012.

JANSEN, D.C. Perfil geoecológico da Área de Proteção Ambiental (APA) do Morro da Pedreira e do Parque Nacional (PARNA) da Serra do Cipó/MG. Caderno de Geografia, v.24, n. $41, \quad$ p. $67-76, \quad 2014$. https://doi.org/10.5752/P.23182962.2014v24n41p66

LAMOUNIER, W. L. et al. A influência da litologia na distribuição da cobertura vegetal e no uso do solo na Serra do Gandarela. Geografias, v. 6, n. 1, p. 152-165, 2010.

LEVIGHIN, S. C.; VIADANA, A. G. Perfisecológicos como técnica para estudo das condições ambientais. Sociedade \& Natureza, v. $14-15$, p. 5-19, 2003.

LOPEZ, G.G.S.; LEÃO, O.M.R. Aspectos geomorfológicos e análise geoecológica em unidades de conservação: estudo de caso do Parque Natural Municipal Montanhas de
Teresópolis. Revista Tamoios, São Gonçalo (RJ), ano 14, n. 2, p. 92 - 116, jul-dez 2018. https://doi.org/10.12957/tamoios.2018.36662

MARENT, B.R.; PORTILHO, S. Unidades de paisagem na bacia hidrográfica do Ribeirão Preto, Serra do Gandarela - MG. GEOUSP (online), São Paulo, v. 21, n. 1, p. 138 - 155, jan./abr.

2017.

https://doi.org/10.11606/issn.2179-

0892.geousp.2017.116477

MARÉS MIKOSIK, A. P. et al. Confecção E Análise Do Perfil Geoecológico Da Bacia Do Rio Sagrado ( Morretes / Pr ). In: SIMPÓSIO BRASILEIRO DE GEOGRAFIA FÍSICA APLICADA - A Geografia Aplicada e as dinâmicas de apropriação da Natureza. Viçosa (MG): [s.n.], 2009.

MEDINA, A. I. DE M.; DANTAS, M. E.; SAADI, A. PROJETO APA SUL RMBH: geomorfologia, mapa geomorfológico, escala 1:50.000. Belo Horizonte: CPRM/EMBRAPA/SEMAD, 2005.

MONTEIRO, C. A. DE F. Geossistemas: a história de uma procura. 2a ed. São Paulo: GeoUSP, 2001.

OLIVEIRA, G. DA S. R.; JACQUES, P. D.; SHINZATO, E. PROJETO APA SUL RMBH: uso e cobertura da terra, mapas cobertura e uso da terra, escala 1:50.000. Belo Horizonte: SEMAD/CPRM, 2005.

PILÓ, L. B.; COELHO, A.; REINO, J. C. R. Geoespeleologia em rochas ferríferas: Cenário atual e conservação. In: CARMO, F. F.; KAMINO, L. H. Y. Geossistemas Ferruginosos do Brasil: áreas prioritárias para conservação da diversidade geológica e biológica, patrimônio cultural e serviços ambientais. Belo Horizonte: 3i Editora, 2015. p. 125-148.

RAMOS, F.; BARREIROS, A.M.; VILLELA, F.N.J.; PINHEIRO, M.R. Análise integrada da paisagem: perfis geoecológicos na transição Planalto Ocidental - Depressão Períférica no município de São Pedro, Estado de São Paulo. Revista do Instituto Geológico, São Paulo, v.40, n.3, p. 75-91, 2019. https://doi.org/10.33958/revig.v40i3.676

SALGADO, A. A. R. Apresentação. In: CARMO, F. F.; KAMINO, L. H. Y. (Org.). Geossistemas Ferruginosos do Brasil: áreas prioritárias para conservação da diversidade geológica e biológica, patrimônio cultural e serviços ambientais. Belo Horizonte - MG: 31 Editora, 2015. p. 9-10. 
SANTOS, D.J. A geodiversidade do Parque Nacional da Serra do Gandarela: Análise do potencial de uso didático, com ênfase no patrimônio espeleológico. Dissertação de Mestrado. Universidade Federal de Minas Gerais, Instituto de Geociências, 2017.

SANTOS, R.S.; LIRA, D.R.; SANTOS, C.A. Seções-tipo e representação integrada das paisagens no estado de Sergipe. Revista Contexto Geográfico, v.3, n. 5, p. 67 - 74, Maceió-AL julho/2018. https://doi.org/10.28998/contegeo.v3i5.6763

SHINZATO, E.; CARVALHO FILHO, A. DE. PROJETO APA SUL RMBH: Estudos do Meio Físico, Pedologia. Belo Horizonte: CPRM/EMBRAPA/SEMAD. , 2005

SOTCHAVA, V. B. O estudo de geossistemas. Instituto de Geografia (Métodos em Questão, 16), p. 51, 1977.

SOUZA, F. C. R. DE; CARMO, F. F. Geossistemas ferruginosos no Brasil. In: CARMO, F. F.; KAMINO, L. H. Y. (Org.). Geossistemas ferruginosos do Brasil:áreas prioritárias para conservação da diversidade geológica e biológica, patrimônio cultural e serviços ambientais. Belo Horizonte: 31 Editora, 2015. p. 47-76.

VALE S.A.; AMPLO ENGENHARIA E GESTÃO DE PROJETOS LTDA. Projeto mapeamento de geoambientes do geossistema ferruginoso do Sinclinal Gandarela - Relatório Técnico Final. [S.l: s.n.]. , 2019

\section{CONTREIBUIÇÃO DOS AUTORES}

Darcy José dos Santos, Úrsula Ruchkys e Luiz Eduardo Panisset Travassos conceberam o estudo. Darcy José dos Santos coletou, analisou os dados e redigiu o texto. Úrsula Ruchkys analisou os dados, supervisiou o estudo e redigiu o texto. Luiz Eduardo Panisset analisou os dados, supervisionou o estudo, redigiu e revisou o texto. 